\title{
Experiences in psychosocial support in disaster situations from developing countries: the Ica - Peru earthquakes of 2008
}

\author{
Alexander A Tarev ${ }^{1 *}$, Tony Donchev${ }^{1}$, Manuel Escalante ${ }^{2}$, Maritza Diaz ${ }^{3}$ \\ From $1^{\text {st }}$ International Congress on Neurobiology and Clinical Psychopharmacology and European \\ Psychiatric Association Conference on Treatment Guidance \\ Thessaloniki, Greece. 19-22 November 2009
}

\section{Background}

After a disaster event, little or no attention is paid to mental and psychosocial implications mainly due to the lack of guidelines and resources for work in the field of mental health in many countries. Advances have been made in developed countries with the capacity to afford research and logistic innovations. In developing countries there has been a constant effort to develop affordable, community-based practices, adjusted to financial and logistic scarcity, and in accordance with the existing cultural barriers.

\section{Materials and methods}

We compiled and analyzed a series of information materials regarding the implementation of mental health services after the 2008 Ica-Peru earthquake, focusing especially on the aspects related to organization of services and accesibilty.

\section{Results}

Although poorly-funded and short-staffed, local health authorities were able to establish mental health and psychosocial support after the disaster event.

This response was based on the framework of the Community oriented primary care model (COPC) which enables the implementation of accessible emergency mental health programs.

The IASC-Guidelines represent a substantial document because of its practical approach especially in economically challenged areas.

COPC also has shown an advantage from a transcultural perspective, giving communities the ability to tackle challenges using available resources in a culturally aware manner.

\section{Conclusions}

Development of programs for mental health services in disaster situations cannot be based only on pure innovative spirit. Attention has to be pointed to the availability resources, as well as take in account cultural and ethnic barriers.

\section{Author details}

${ }^{1}$ Psychiatry clinic, Military Medical Academy, Sofia, Bulgaria. ${ }^{2}$ Direction of Mental Health, Ministry of Health, Lima, Peru. ${ }^{3}$ Ica Regional Health Direction, Ica, Peru.

Published: 22 April 2010

References

1. Bhugra D: Psychiatry and disaster: paradoxical relationship. Int J SoC Psychiatry 2005, 51(3):195-7.

2. Bhui $\mathrm{K}$, et al: Cultural competence in mental health care: a review of model evaluations. BMC Health Serv Res 2007, 7:15.

3. Gofin J, Gofin R: Atención primaria orientada a la comunidad: un modelo de salud pública en la atención primaria. Revista Panamericana de Salud Pública 2007, 21:177-185.

4. IASC, I-ASC: IASC Guidelines on Mental Health and Psychosocial Support in Emergency Settings. Inter-Agency Standing Committee IASC: Geneva 2007

doi:10.1186/1744-859X-9-S1-S187

Cite this article as: Tarev et al:: Experiences in psychosocial support in

disaster situations from developing countries: the Ica - Peru

earthquakes of 2008. Annals of General Psychiatry 2010 9(Suppl 1):S187.

${ }^{1}$ Psychiatry clinic, Military Medical Academy, Sofia, Bulgaria 